\title{
Student Centered Education
}

Self-organized Learning Environments and the

Future of Student-centered Education

From the Life and Health Sciences Research Institute (ICVS), ICVS/ 3B's-PT Government Associate Laboratory, School of Health Sciences, University of Minho, Gualtar Campus, Braga, Portugal

Children are able to achieve sophisticated learning without teachers. Such is the main message of the "hole in the wall" tests that have led to the concept of "self-organized learning environments" (SOLEs) [1]. "Hole in the wall" refers to "computers set up in public places such as streets and playgrounds for unsupervised use by children.” There have been numerous trials developed in remote places in countries such as India, Bhutan, and the Republic of Central Africa, in which "kiosks" with computers connected to the internet have been set up for whoever wishes to use them. In a number of experiments, this "minimally invasive education" has been demonstrated to result in surprising learning achievements in children, in subjects such as English language, computer processing, and molecular biology [2]. What is fascinating about the concept is that all learning happens with no teaching by teachers. Remarkably, test performances of students who have learned in SOLE may match those of students who have learned in schools, suggesting that schools and SOLEs can result in identical learning [3].

Sugata Mitra, the author of the experiments provides several lines of argument to the benefit of SOLE that also apply to higher education. He considers that schools are obsolete as they prepare citizens to fulfill certain specific and defined professional roles. Given the fast pace in which professions change nowadays, even the most dynamic schools may be preparing graduates to work in the past. Another strong argument is that nowadays, students access learning materials not from what teachers select as study materials, but too often through individual browsing with mobile devices and tablets. Students are often excited with what "the cloud" has to offer, and relatively unexcited with what the school has programmed for them. There is a social networking explosion happening today. Students are

\footnotetext{
*Address for correspondence to: Life and Health Sciences Research Institute (ICVS), ICVS/3B's—PT Government Associate Laboratory, School of Health Sciences, University of Minho, Gualtar Campus, Braga, Portugal. E-mail: mmcosta@ecsaude.uminho.pt. Received 17 January 2014; Accepted 20 January 2014 DOI 10.1002/bmb.20781

Published online 12 February 2014 in Wiley Online Library

(wileyonlinelibrary.com)
}

often learning online with one another, as members of educational communities. Dr. Mitra's last argument is that we may be running into a future in which one who knows the information is not as well prepared to succeed as one who is proficient in accessing and quickly incorporating reliable information into pre-exiting knowledge: "knowing is obsolete."

Learning, according to Dr. Mitra, is a product of a selforganizational educational process. "It is not about making learning happen, it is about letting it happen." Within a SOLE paradigm, power would shift decisively to students, as all choices-study resources, examples that might be used in class, criteria to be applied to measure a certain course proficiency-would be made by students. What may the SOLE paradigm offer to paradigms of student-centered education?

Student-centered education is about teachers investing in the development of the learners' potential rather than in selecting the absolute chunks of content to pass on to students. It is about using teaching strategies that consider the students' needs and interests, confer more power to students, assign new roles for the teacher and, last but not least, make students take responsibility for their own learning. The student-centered paradigm emerged as an alternative to the so called "traditional" or "teacher-centered" instruction. Even though the two paradigms are fundamentally different, they share important characteristics. Both paradigms depend on a physical infrastructure-the school, the university-where teachers and students meet in classrooms, rely on teachers to define the course's programoutcomes, objectives, content, curriculum, and so forthand assessments. Even though the two paradigms see the teachers and students very differently, the existence of the two roles is quintessential for both: teachers must teach somehow so students can learn. This is true for any of the established student-centered educational approaches-such as Team Based Learning, Peer Instruction, or Problem Based Learning. None considers the possibility of no teaching delivered by teachers or that of no teachers at all. The SOLE projects and derived research show that children who were not educated with computers may learn by themselves, if they are given access to the world wide web. If this is possible for children in remote countries, what can 
students actually achieve if we let them take full responsibility for developing their learning?

\section{References}

[1] Mitra, S. (2003) Minimally invasive education: A progress report on the 'Hole-in-the-wall' experiments. Br. J. Educ. Technol. 34, 367-371.
[2] Mitra, S. and Dangwa, R. (2010) Limits to self-organising systems of learning-The Kalikuppam experiment. Br. J. Educ. Technol. 41,672688.

[3] Mitra, S., Dangwa, R., Chatterjee, S., Jha, S., Bisht, R. S., Kapur, P. (2005) Acquisition of computer literacy on shared public computers: Children and the "Hole in the wall", Australas. J. Educ. Technol. 21, 407-426. 